\title{
Analysis of energy use and greenhouse gas emissions (GHG) of transplanting and broadcast seeding wetland rice cultivation
}

\begin{abstract}
The analysis of energy and greenhouse gas emissions in this study was made in respect to both planting methods, transplanting and broadcast seeding methods to investigate the energy pattern of rice production in Malaysia. The field under transplanting method in the main season showed $8.72 \%$ lesser mean total energy input, $6.25 \%$ higher mean machinery energy, $55.06 \%$ lesser mean seed energy and $23.01 \%$ higher mean output energy than the field under broadcasting method. Fertilizer the highest contributor of energy inputs it contributed by $62 \%$ in both transplanting and broadcasting methods and fuel was the second-highest contributor. The share of direct and indirect energy in the fields under the transplanting method were $19 \%$ and $81 \%$ and in the fields under the broadcasting method were $17 \%$ and $83 \%$ respectively. While the share of renewable and non-renewable energy in the fields under the trans-planting method were $7 \%$ and $93 \%$ and in the fields under the broadcasting method were $14 \%$ and $86 \%$ respectively. The harvesting operation has the highest mechanization index level (0.99) in both methods. While fertilizing and planting operation have the lowest mechanization index level. The mean energy ratio was $35.68 \%$ higher in transplanting than broadcasting $(8.1$ and 5.97). Fertilizer represents the highest contributor to the total GHG emissions in the two cultivation methods, transplanting and broadcasting and it represents $44 \%$ and $42 \%$ respectively. Among different types of chemical fertilizers, Nitrogen represents the higher contributor.
\end{abstract}

Keyword: Energy analysis; Energy ratio; Renewable energy; Mechanization index; Greenhouse gas emissions (GHG) 